\title{
Explicit calculation of indirect global warming potentials for halons using atmospheric models
}

\author{
D. Youn ${ }^{1,2}$, K. O.Patten ${ }^{1}$, J.-T. Lin ${ }^{3}$, and D. J. Wuebbles ${ }^{1}$ \\ ${ }^{1}$ Dept. of Atmospheric Sciences, University of Illinois at Urbana-Champaign, 105 S. Gregory St., Urbana, IL 61801, USA \\ ${ }^{2}$ School of Earth \& Environmental Sciences, Seoul National University, 599 Gwanak-ro, Gwanak-gu, Seoul 151-747, \\ Republic of Korea \\ ${ }^{3}$ School of Engineering and Applied Sciences, Harvard University, 19 Oxford St., Cambridge, MA 02138, USA
}

Received: 23 April 2009 - Published in Atmos. Chem. Phys. Discuss.: 21 July 2009

Revised: 28 October 2009 - Accepted: 1 November 2009 - Published: 16 November 2009

\begin{abstract}
The concept of Global Warming Potentials (GWPs) has been extensively used in policy consideration as a relative index for comparing the climate impact of an emitted greenhouse gas (GHG), relative to carbon dioxide with equal mass emissions. Ozone depletion due to emission of chlorinated or brominated halocarbons leads to cooling of the climate system in the opposite direction to the direct warming contribution by halocarbons as GHGs. This cooling is a key indirect effect of the halocarbons on climatic radiative forcing, which is accounted for by indirect GWPs. With respect to climate, it is critical to understand net influences considering direct warming and indirect cooling effects especially for Halons due to the greater ozone-depleting efficiency of bromine over chlorine. Until now, the indirect GWPs have been calculated using a parameterized approach based on the concept of Equivalent Effective Stratospheric Chlorine (EESC) and the observed ozone depletion over the last few decades. As a step towards obtaining indirect GWPs through a more robust approach, we use atmospheric models to explicitly calculate the indirect GWPs of Halon-1211 and Halon-1301 for a 100-year time horizon. State-of-theart global chemistry-transport models (CTMs) were used as the computational tools to derive more realistic ozone depletion changes caused by an added pulse emission of the two major Halons at the surface. The radiative forcings on climate from the ozone changes have been calculated for indirect GWPs using an atmospheric radiative transfer model (RTM). The simulated temporal variations of global average total column Halons after a pulse perturbation follow an exponential decay with an e-folding time which is consistent with the expected chemical lifetimes of the Halons. Our cal-
\end{abstract}

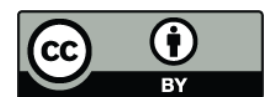

Correspondence to: D. J. Wuebbles (wuebbles@atmos.uiuc.edu) culated indirect GWPs for the two Halons are much smaller than those from past studies but are within a single standard deviation of WMO (2007) values and the direct GWP values derived agree with the published values. Our model-based assessment of the Halon indirect GWPs thus confirms the significant importance of indirect effects on climate.

\section{Introduction}

As a family of atmospheric gases, chlorinated and brominated halocarbons, including the human-produced chlorofluorocarbons (CFCs) and bromofluorocarbons (often refered to as Halons), are all greenhouse gases (GHGs) in that they trap outgoing longwave radiation in the troposphere that would otherwise escape to space. This trapped radiation warms the atmosphere, creating a positive forcing on the climate system, which in turn warms the Earth's surface. The concept of radiative forcing provides an estimate of the potential effect on climate from GHGs. For the given concentration of a gas, the radiative forcing depends primarily on the infrared absorption capacity of the gas.

Since it was developed for the first scientific assessment of the Intergovernmental Panel on Climate Change (IPCC) in 1990, the concept of Global Warming Potentials (GWPs) has been used as a relative index for comparing the potential climate impact of different GHGs to a reference gas such as $\mathrm{CO}_{2}$ (IPCC, 1990, 2001, 2007; WMO, 2003, 2007). Although the concept of GWPs has well recognized uncertainties and limitations of its own (e.g., see Wuebbles, 1995), GWPs are a better measure of the relative climate impacts than radiative forcing alone as they also account for the atmospheric lifetime of the gases and thus the temporal change in concentration for a given emission. Numerical models of

Published by Copernicus Publications on behalf of the European Geosciences Union. 
atmospheric chemistry and physics have been used to determine the atmospheric lifetimes and radiative forcings for the various compounds, and thus the GWPs have been evaluated and reported for a number of replacement compounds in the international assessments (IPCC, 2001, 2007; IPCC/TEAP 2005; WMO, 1999, 2003, 2007). GWPs are also being used in policymaking considerations associated with concerns about climate change associated with GHGs, generally using the values for a 100-year integration time.

Of all GHGs, halocarbons tend to have very high GWPs, as much as ten thousand times the warming effect of carbon dioxide (see Tables of Forster et al., 2007 and Daniel and Velders, 2007). However, unlike carbon dioxide and some of the other GHGs, these gases play a significant role in the chemistry of stratospheric ozone when the halocarbon molecules are broken down to release chlorine or bromine atoms in the stratosphere. The distribution of ozone also has important implications for the Earth's climate system, not only because ozone absorbs solar radiation but also because it acts as a greenhouse gas that helps warm the Earth by absorbing some of the outgoing infrared radiation emitted from the Earth's surface. Changes in both the distribution and overall abundance of ozone can affect climate. Therefore, stratospheric ozone losses by increased halogen atoms can decrease the temperature of the lower stratosphere, resulting in a decreased infrared flux to the troposphere, reducing some or all of the positive radiative forcing effects caused by the increased infrared trapping of the halocarbons. The cooling effect through ozone destruction can even exceed the direct warming effect of the halocarbons as GHGs (Lacis et al., 1990; Ramaswamy et al., 1992) and could possibly lead to net cooling of the climate system. This cooling effect through ozone destruction is a key indirect effect of halocarbons on radiative forcing and is particularly significant for bromine-containing gases due to the larger efficiency of bromine over chlorine for ozone depletion. The indirect climate impact, accounted for by indirect GWPs, decreases the GWPs of these halocarbons. However, this is an overly simplified viewpoint as the climate effects of a change in radiative forcing for ozone are known to depend on the specific spatial changes in the ozone distribution.

Daniel et al. (1995) introduced a method to estimate the indirect GWPs for various halocarbons. The indirect GWP values, included in all international environmental assessments to date (IPCC/TEAP, 2005; WMO 1995, 1999, 2003, 2007), have been estimated from the traditional approach developed by Daniel et al. (1995). However, the traditional approach is based on two assumptions: (1) a linear relationship between the changes in equivalent effective stratospheric chlorine (EESC) and in radiative cooling due to the lower stratospheric ozone loss and (2) a threshold for ozone depletion such that ozone loss ends when EESC falls below 1980 levels. The concept of EESC has limitations because of uncertainties in the transport time, the bromine efficiency for ozone destruction versus chlorine $(\alpha)$, the efficiency of stratospheric halogen release of the source gas, the starting date for ozone depleting substance (ODS) release, the emissions scenarios assumed, possible temporal changes of transport times, and fractional bromine/chlorine releases (Newman et al., 2006, 2007). The reported indirect GWPs have primarily changed over time as a response to updates in the EESC and updates to the carbon dioxide mixing ratio and response function. It is apparent that the indirect GWP calculated by the approach in Daniel et al. (1995) is very sensitive to uncertainties in EESC and associated radiative forcing. Combined "net" GWPs were reported only in IPCC/TEAP (2005) because the direct and indirect climate responses cannot be easily added to a climate response due to possibly different spatial dependences (Joshi et al., 2003).

A recent reformulation of the method for estimating the EESC was provided that better accounts for the age-of-air spectrum and the age-of-air dependent fractional release values (Newman et al., 2007). Although the new EESC formulation and the sensitivity to above-mentioned uncertain parameters have been explored (Newman et al., 2007), the use of the EESC is still limited by the underlying assumptions and the simplification of the complex processes occurring in the atmosphere. Of special concern is that the EESC only provides a rough estimate of the time scale of global ozone change in an unchanging atmosphere without consideration of actual chemical, physical and transport processes in the troposphere and stratosphere. Therefore, their approach should not be regarded as a perfect gauge in evaluating ozone change related to ozone depleting substances (ODS) releases and future ozone levels. Along with the uncertainties in EESC concept, the assumption of a linear relationship between changes in the EESC and changes in radiative forcing could itself lead to potentially significant errors in estimating the indirect GWPs.

As a step toward obtaining indirect GWPs through a more robust approach, the indirect cooling effects are explicitly evaluated here for several halocarbons using state-of-the-art atmospheric models. In this study, the model-based indirect GWPs of the two major Halons, Halon-1211 $\left(\mathrm{CF}_{2} \mathrm{ClBr}\right)$ and Halon-1301 $\left(\mathrm{CF}_{3} \mathrm{Br}\right)$, for a 100-year time horizon have been calculated. To derive ozone changes with time, following (caused by) a pulse perturbation emission for each Halon at the surface, we use the National Center for Atmospheric Research (NCAR) Model for OZone And Related Tracers version 3 (MOZART-3) three-dimensional (3D) CTM (Kinnison et al., 2007) as well as the University of Illinois at Urbana-Champaign (UIUC) two-dimensional (2D) CTM (Li et al., 2006). The UIUC radiative transfer model (RTM) was then used to calculate the temporal changes in radiative forcing through the ozone loss over the CTM integration time.

The use of state-of-the-art numerical models of the chemistry and physics of the troposphere and stratosphere is indispensable to improve and expand upon the understanding of the effects of human-related emissions of atmospheric gases 
on the atmospheric ozone layer and its relationship to climate change. This paper is organized as follows. A brief description of the models used for our calculations is presented in Sect. 2. The methodology to obtain indirect GWPs for Halons is described in Sect. 3. Time-dependent changes in each perturbed Halon and resulting ozone destruction are presented in Sect. 4. The direct GWPs from the changes in perturbed Halons and the indirect GWPs from changes in ozone radiative forcing are estimated in Sect. 5. The discussions and conclusions are found in Sect. 6.

\section{Models}

\subsection{Global atmospheric chemistry-transport models}

The University of Illinois at Urbana-Champaign (UIUC) 2-D CTM is a zonally-averaged model for the chemistry, physics, and transport of the global atmosphere. It has often been used to study human-related and natural forcings on the troposphere and stratosphere (e.g., Wuebbles et al., 2001; Li et al., 2006) and has been used in many past WMO ozone assessments. It has the advantage of being much more computationally efficient than 3-D CTMs. It captures the most important physical and chemical processes of the global atmosphere relatively well, especially for the long-lived chemical compounds. Owing to its computational efficiency, we could perform 100-year model simulations that allowed us to do initial analyses and understand effects of perturbed Halons on ozone. It is always noted that the 2-D model has limitations in adequately representing the zonally asymmetric features such as tropospheric transport processes and the edge and evolution of the ozone hole. However, the limitations of the 2-D model should not greatly affect this study since the Halons are long-lived species (lifetimes larger than 10 years) enough to be relatively well mixed in the troposphere. As an initial attempt at evaluating the indirect GWPs using atmospheric models, the 2-D CTM is thus an efficient tool for evaluating the time-dependent ozone changes caused by emissions of Halons instantaneously added into the atmosphere for direct and indirect GWPs over a 100-year time horizon.

The version of the UIUC 2-D model used in this study simulates the atmospheric distributions of 78 chemically active atmospheric trace constituents with 56 photolytic reactions and 161 thermal reactions (for detailed descriptions on model chemistry and physics, see Kotamarthi et al., 1999; Wuebbles et al., 2001; Li et al., 2006). Heterogeneous chemistry processes involving polar stratospheric clouds (PSCs) are included using time-dependent parameterization of PSCs (Considine et al., 2000). Reaction-rate constants and photochemical data in the model are primarily based on the recommendations compiled by the NASA Panel for Data Evaluation (DeMore et al., 1997; Sander et al., 2003). The model domain extends from pole to pole and from the ground to
$84 \mathrm{~km}$ in altitude. A grid box covers $5^{\circ}$ of latitude and $1.5 \mathrm{~km}$ in log-pressure altitude. The zonally averaged temperature and wind fields are specified based on the 10-year climatology of the United Kingdom Meteorological Office (UKMO) reanalysis data (Coy and Swinbank, 1997; Youn et al., 2006).

A state-of-the-art 3-D CTM, Model for OZone And Related Tracers (MOZART) version 3 (see Horowitz et al., 2003; Kinnison et al., 2007), was also used to explicitly calculate ozone changes caused by the same pulse emission of Halons. The computationally expensive 3-D model better represents some of the physical processes affecting ozone, especially in the troposphere. The MOZART-3 is an extension of the previous MOZART version (Horowitz et al., 2003) developed for studies of both troposphere and upper atmosphere that has been documented by Kinnison et al. (2007). MOZART is a well-established threedimensional CTM developed by a collaboration among researchers at the National Center for Atmospheric Research and other institutions including the University of Illinois at Urbana-Champaign that has been applied to numerous studies of the atmosphere (e.g. Kinnison et al., 2007; Pan et al., 2007) and to human effects on atmospheric composition (e.g. Wuebbles and Patten, 2009). The MOZART-3 coordinates follow those of the input meteorology from the NCAR Whole-Atmosphere Community Climate Model version $1 \mathrm{~b}$ (WACCM 1b) for this study. The vertical domain ranges from the surface to $5.1 \times 10^{-6} \mathrm{hPa}$ (approximately $140 \mathrm{~km}$ ) in a hybrid sigma-pressure coordinate. The model as used in this study uses 128 longitude points and 64 latitude points for a resolution of $2.8^{\circ}$ in both latitude and longitude and 66 vertical levels. Meteorological fields calculated in WACCM $1 \mathrm{~b}$ (Sassi et al., 2002) serve as input to the MOZART advective transport and internal calculation of convection, clouds, and wet deposition. The WACCM $1 \mathrm{~b}$ model year of output was selected as an average meteorology at a time resolution of three hours from a run that used boundary conditions representative of 1999 (Garcia et al., 2007).

The standard MOZART-3 chemistry includes 106 gasphase species and is largely based on the 2002 JPL panel photochemical data evaluation (Sander et al., 2003). The surface boundary conditions for both mixing ratios of longlived source gases (methane $\mathrm{CH}_{4}$, nitrous oxide $\mathrm{N}_{2} \mathrm{O}$, hydrogen $\mathrm{H}_{2}$, methyl chloride $\mathrm{CH}_{3} \mathrm{Cl}$, methyl bromide $\mathrm{CH}_{3} \mathrm{Br}$, and chloro- and bromofluorocarbons) and fluxes of short-lived source gases $\left(\mathrm{NO}_{\mathrm{x}}\right.$, carbon monoxide $\mathrm{CO}$, hydrocarbons including ethane and ethylene, and oxygenated hydrocarbons such as acetone $\left.\mathrm{CH}_{3} \mathrm{C}(\mathrm{O}) \mathrm{CH}_{3}\right)$ in this study are selected to represent the year 1999. Surface mixing ratios for long-lived species are based on Table 8-5 in Daniel et al. (2007), and surface fluxes of short-lived species with their geographic and seasonal distributions are based on the POET (Precursors of Ozone and their Effects in the Troposphere) emissions data base (Pfister et al., 2008). 
Both models have been extensively evaluated relative to available measurements of ozone and other relevant gases in the troposphere and stratosphere (e.g., Kinnison et al., 2007; Pan et al., 2007). Comparisons of monthly zonal mean total column ozone simulated by the UIUC 2-D model with the Solar Backscatter Ultraviolet Ozone Sensors (SBUV and SBUV/2) measurements indicate good agreement in the variation with time and the model is generally within $1 \%$ of the data (Miller et al., 2002; Guillas et al., 2004). Ozone mixing ratios and total column ozone simulated by the MOZART-3 have been compared to various observational datasets (e.g., Kinnison et al., 2007). Despite differences dependent on the choice of meteorology inputs, the MOZART-3 simulated total ozone columns generally agree well with observations. We thus argue that the ozone processes as calculated by the UIUC 2-D and the MOZART-3 3-D CTMs can be reasonably adopted for this study.

\subsection{Radiative transfer model}

The UIUC radiative transfer model (RTM) version 2.3.6 calculates radiative fluxes across the tropopause for atmospheric inputs derived from the MOZART and UIUC 2-D CTMs. Earlier versions of the UIUC RTM have been used in studies of climate effects and in the derivation of GWPs (Jain et al., 2000; Naik et al., 2000). The current version incorporates several improvements over those versions, notably that solar radiation can now be optionally handled with the DISORT multi-stream radiative transfer kernel (Stamnes et al., 1988). The UIUC RTM has been developed to evaluate radiative properties of the outputs from global atmospheric chemicaltransport models, such as the UIUC 2-D, the MOZART 3-D, and the NASA Global Modeling Initiative (GMI) 3-D models, which contain air temperature and mixing ratios of the radiatively active constituents carbon dioxide $\left(\mathrm{CO}_{2}\right)$, water vapor $\left(\mathrm{H}_{2} \mathrm{O}\right)$, ozone $\left(\mathrm{O}_{3}\right)$, methane $\left(\mathrm{CH}_{4}\right)$, nitrous oxide $\left(\mathrm{N}_{2} \mathrm{O}\right)$, and various halocarbons.

For shortwave radiation calculation, similar to the solar and terrestrial radiative transfer models from which it was originally created (Briegleb, 1992a, 1992b), the solar spectrum is divided into 18 bins from $0.2-5.0$ micrometers, with solar flux fractions specified for each bin. Included in the calculation are molecular, cloud, and surface scattering, along with $\mathrm{H}_{2} \mathrm{O}, \mathrm{O}_{3}, \mathrm{CO}_{2}, \mathrm{O}_{2}$, clouds, and surface absorption. The longwave radiation heating rates and boundary fluxes calculation utilizes a narrow band model (NBM), which computes narrow band absorptivity and emissivity over $10 \mathrm{~cm}^{-1}$ intervals from 0 to $3000 \mathrm{~cm}^{-1}$ for water vapor and $5 \mathrm{~cm}^{-1}$ from 0 to $3000 \mathrm{~cm}^{-1}$ for other gases and then sums them up to obtain the broad band radiative forcings. Orography and surface albedo are based on observations, while clouds are based on the International Satellite Cloud Climatology Project (ISCCP) climatology and tropopause height on the National Centers for Environmental Prediction (NCEP) reanalysis. The HITRAN (high resolution transmission) 2004 database (Rothman et al., 2005) provides spectral data for the radiatively active species, which are averaged to the spectral intervals within the UIUC RTM.

\section{Methodology}

\subsection{Indirect Global Warming Potential (GWP)}

The indirect cooling effect of the two major Halons on climate arising from ozone depletion can significantly cancel the direct global warming effect of these GHGs. The indirect GWPs are of special interest because of their potential use related to ozone and climate. However, the existing approach to estimating indirect GWPs has significant limitations due to the parameterization approach and underlying assumptions, as explained earlier. Therefore, in this study the indirect GWPs are evaluated through explicit calculations using state-of-the-art atmospheric models.

Our model-based analyses of indirect GWPs are derived based on the classical definition of GWPs. Since the first scientific assessment (IPCC, 1990), the GWP has been used as a relative index for comparing the potential climate impact of one greenhouse gas to another, based on globally averaged radiative forcing of the climate system over a specified time scale. GWPs are expressed as a ratio of the timeintegrated radiative forcing from the instantaneous release of a kilogram of a gas relative to that of a kilogram of the reference gas, generally carbon dioxide, over a fixed time horizon (IPCC/TEAP, 2005; IPCC, 2007; WMO, 2007). Thus, the direct Global Warming Potential of a gas $\chi$ (IPCC, 1990, 2001) can be defined as:

$\mathrm{GWP}_{\chi}(\mathrm{TH})=\frac{\int_{0}^{\mathrm{TH}} F_{\chi} \cdot[\chi(t)] d t}{\int_{0}^{\mathrm{TH}} F_{\mathrm{CO}_{2}} \cdot\left[\mathrm{CO}_{2}(t)\right] d t}$

where $\mathrm{TH}$ is the integration time (the time horizon) over which the calculation is performed, $F_{\chi}$ is the radiative forcing efficiency due to a unit mass change in the atmospheric abundance of the substance $\chi$, and $[\chi(t)]$ describes the timedependent decay of the abundance from an instantaneous release of gas $\chi \cdot F_{\chi}$ and $F_{\mathrm{CO}_{2}}$ are generally given in units of $\mathrm{W} \mathrm{m}{ }^{-2} \mathrm{~kg}^{-1}$.

Time-dependent changes in radiative forcing, resulting from ozone depletion caused by an emission of chlorine and bromine-containing species $\chi$, are key indirect effects of the gas on radiative forcing. If the numerator in the Eq. (1) is substituted with the time-integration of the time-dependent changes in radiative forcing due to ozone depletion following an instantaneous release of a kilogram of halocarbon $\chi$, then the resulting GWP becomes the indirect GWP of $\chi$ through ozone depletion.

In this study, the evaluation of indirect GWPs for Halon1211 and Halon-1301 over the 100-year time horizon has been accomplished in three steps: (1) time-dependent simulation of an instantaneously perturbed Halon and ozone 
response to the additional Halon pulse release using atmospheric CTMs; (2) calculation of radiative forcing using an atmospheric RTM; and (3) evaluation of a 100-year direct and indirect GWP. The MOZART-3 3-D and the UIUC 2D CTMs are used as the computational tools for deriving ozone changes after an instantaneous surface release (oneyear pulse perturbation emission) of the given Halon. Radiative forcing changes induced by the time-dependent ozone losses during the model simulations over the time-horizon are calculated with the UIUC RTM. To obtain complete 100year changes in atmospheric concentrations and radiative forcing for the 3-D simulations, exponential curve fits have been applied as described in following sections for the two purposes of validating model simulations and filling in the tail part of remaining years.

\subsection{Model setup and simulations}

From initial analyses of the indirect GWPs for the Halons, we found that a correct CTM simulation of ozone responses to Halon perturbations requires two prerequisite conditions: (1) a pulse perturbation injection of Halon emissions at the surface rather than a traditional treatment of lower boundary condition (LBC), specifying mixing ratios in the lowest model layer, in CTMs for long-lived species (explained below) and (2) a starting CTM reference atmosphere that is in steady-state. A one-year surface perturbation pulse at the first year of model simulation needs to be put into the model atmosphere in a steady-state.

The traditional CTM setup to represent the perturbation of a long-lived source gas, using a change of the specified concentration in the lowest model layer, cannot be applied to this study of evaluating time-dependent effect of a Halon perturbation on ozone. This is because the model setup mixes the chemical compound unrealistically too fast by constraining the lower boundary with a fixed concentration and so atmospheric temporal variations of the compound are confined by the lower boundary concentration of the compound. Specifying boundary concentration of a compound is also like continuously accumulating additional perturbations at the lower boundary, resulting in faster response of confining whole atmospheric distribution in shorter time. In other words, the model setup does not represent the actual atmospheric behavior since the specified concentrations at the lower boundary override the mixing processes or interaction of the compound at the surface and higher levels. This makes the model atmosphere respond to the given Halon perturbation too fast because the specified concentrations also act as another perturbation added and even accumulated up to the equilibrium of the model atmosphere. Model simulations of Halon perturbation were therefore revised to obtain reasonable timedependent atmospheric response to a single-year pulse perturbation. In this study, the approach with surface flux LBCs for Halons was newly implemented into the CTMs as means of atmospheric loading of the Halons. However, it requires a lot more years of simulations (and thus much more computational time) for CTMs with the new Halon LBC. This is because atmospheric Halon and stratospheric ozone respond to the surface perturbation more slowly as the change in model LBCs represents more realistic mixing and transport processes from the surface to high altitudes.

The change in the LBC of the CTMs also requires additional model runs to start the perturbation simulations from a steady-state model atmosphere with an unperturbed normal amount of surface Halon emission (comparable to the approach of specifying the mixing ratios at the lower boundary). For the 2-D surface perturbation simulations of Halon1211 and Halon-1301, it requires about 30 and 60 years, respectively, to reach a steady-state atmosphere even before perturbations are actually injected. If the perturbation run does not start from a steady-state, the resultant changes in radiative forcing during model simulation period, especially before peak ozone loss, will not be correctly obtained since the starting atmosphere was already in a perturbed state and the impacts of pre-existing Halons on the stratospheric ozone remain.

The extensive computational time in getting to a steadystate in the 3-D model led us to detour this issue by a new simulation method of simultaneously conducting two parallel simulations for the 'standard' and "perturbed" atmospheres, respectively. The starting-point atmosphere of the standard simulation, same with that of the perturbation simulation, is in a perturbed state as a result of the new implementation of surface flux emissions. While the standard model atmosphere comes closer to a steady-state during the model integration, the perturbation simulation responds more to the pulse injection imposed at the surface upon standard flux emissions. Ozone changes over the model integration time in the perturbation simulation, only resulting from the instantaneous pulse emission injection into the starting-point atmosphere, can be derived by subtracting the standard simulation from the perturbation simulation. This subtraction minimizes the errors related to the drifting initial model atmosphere coming from the change in the model LBC setup, which are shown with our simulations in the next section.

In addition, it is not feasible to conduct the MOZART-3 3-D simulations for 100 years as done with the 2-D CTM, due to the high computational demand and limited computing resources. Fortunately, from the initial analyses with the UIUC 2-D CTM, we find that stratospheric ozone destructions due to Halon-1211 and Halon-1301 pulse perturbations recover exponentially after the time of peak loss. From the 2-D analyses, we also find that the 100 -year cumulative decrease of ozone can be projected with less than $20+\alpha(30+\alpha)$ years integration of Halon-1211 (Halon-1301) perturbation. Thus, we expect that $20+\alpha(30+\alpha)$ years of 3-D simulations enable us to estimate approximate 100 years of total radiative forcing for Halon-1211 (Halon-1301) through the application of exponential curve fitting to the tail part of the radiative forcing changes corresponding to the ozone recovery. The 


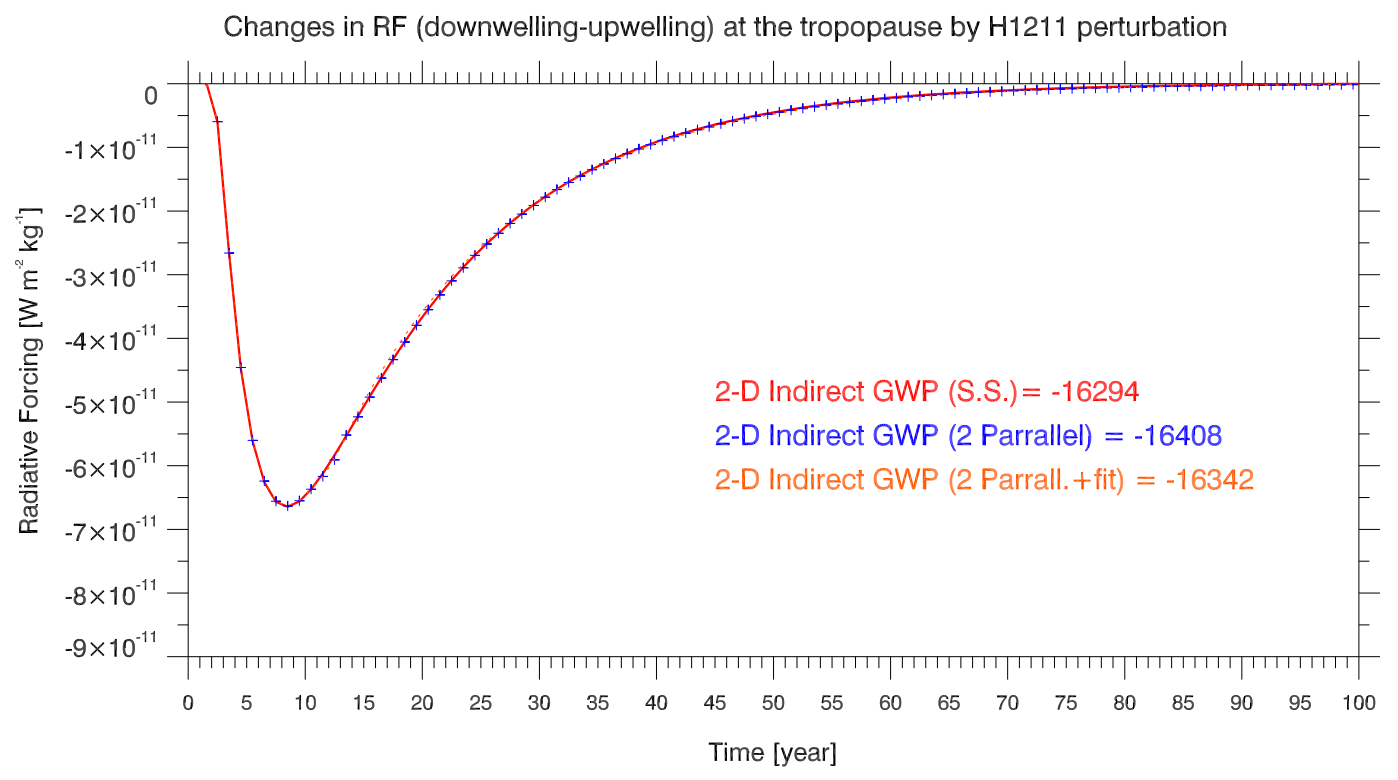

Fig. 1. Time-series of RF changes at the tropopause by three Halon-1211 perturbation experiments: (1) a 100-year simulation starting from a steady-state atmosphere (red), (2) two parallel 100-year simulations starting from an arbitrary atmosphere (blue cross), and (3) two parallel 23-year simulations and curve fit (orange dot).

final radiative forcing changes over the full integration time should be properly obtained by calculating the differences in temporal variations of ozone radiative forcing between the perturbation and the standard simulations.

With this approach, the 3-D indirect GWP of the Halon1211 (Halon-1301) for a 100-year time horizon has been estimated based on 23 (32) years of perturbation simulations along with 8 (14) years of standard simulations.

The robustness of our proposed method has been checked further by perturbation simulations for Halon-1211 using the 2-D model. Three Halon-1211 experiments using the UIUC 2-D CTM were done, including: (1) a 100-year simulation starting from a steady-state atmosphere, (2) two parallel 100year simulations starting from an arbitrary atmosphere, and (3) two parallel 23-year simulations plus curve fit resulted in almost same RF changes in a 100-year time horizon (Fig. 1). The resulting indirect GWPs are in almost perfect agreement, with values of $-16294,-16402$, and -16342 , respectively.

\section{Model Results}

\subsection{Halon perturbation and direct GWP}

A one-year pulse perturbation of each Halon is injected into the surface air during the first year of the 2-D and 3-D model simulations. The starting-point model atmosphere is at steady-state for the 2-D model but not for the 3-D model. The two parallel 3-D simulations of standard and perturbation cases are thus conducted as described in the previous section.
Changes in global total mass of Halon-1211 and Halon1301 over time after the first year pulse injections into 2-D and 3-D model simulations are shown in Fig. 2. The timedependent 2-D (3-D) simulation of Halon-1211 is denoted in red (blue) color. Global total masses of both Halons in the model atmosphere reach maxima at the second model year, while the photolytic break-down of the added Halons transported into the stratosphere leads to Halon reductions in the following years. They show exponential decrease after the second year peak. Exponential curve fitting was applied and the curve shows a lifetime (e-folding time) of 14.4 (10.9) years for 2-D (3-D) model-determined Halon-1211 variation, which is consistent with 14.8 (11.2) years of model derived chemical lifetime, as calculated from total atmospheric loading over chemical loss rates (see Table 1). The modeled efolding lifetimes of Halon-1301 are also in good agreement with the chemical lifetimes. Curve fits applied to the 3-D simulated Halons serve to fill in the remainder of a 100-year time horizon.

Since photochemical data used in 2-D and 3-D CTMs for photolytic reactions of Halons are consistent, the shorter lifetimes of 3-D simulated Halons can be explained by the faster transport and mixing into the stratosphere in that the MOZART-3 3-D model has shorter age of air (Kinnison et al, 2007) than the UIUC 2-D model (Guillas et al., 2004). The 3-D model has about half to one year shorter age of air in the stratosphere, which means faster transport and mixing of the Halons and affected ozone in the stratosphere. Although the 3-D model lifetimes of about 11 years for Halon-1211 are particularly small compared with the 2-D lifetimes of about 
(a) Time-series of global total H1211 mass: 2-D (red) \& 3-D (blue) H1211 perturbation runs

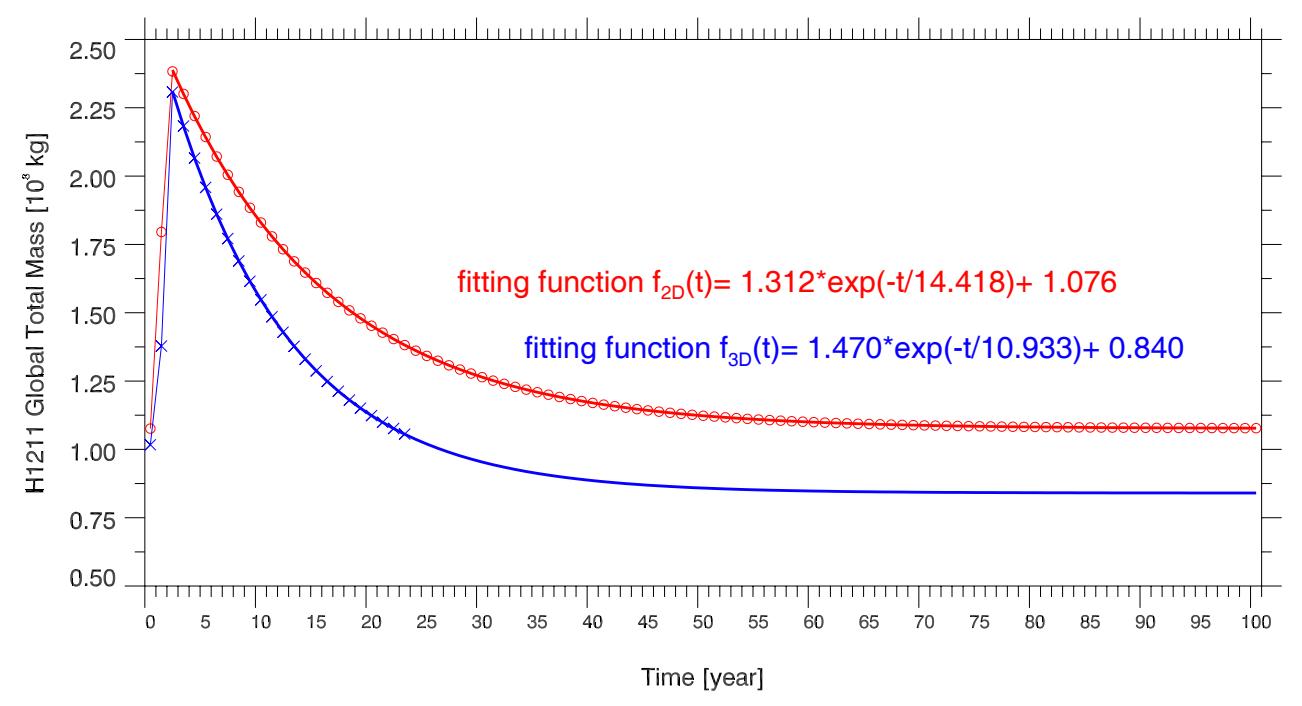

(b) Time-series of global total H1301 mass: 2-D (red) \& 3-D (blue) H1301 perturbation run

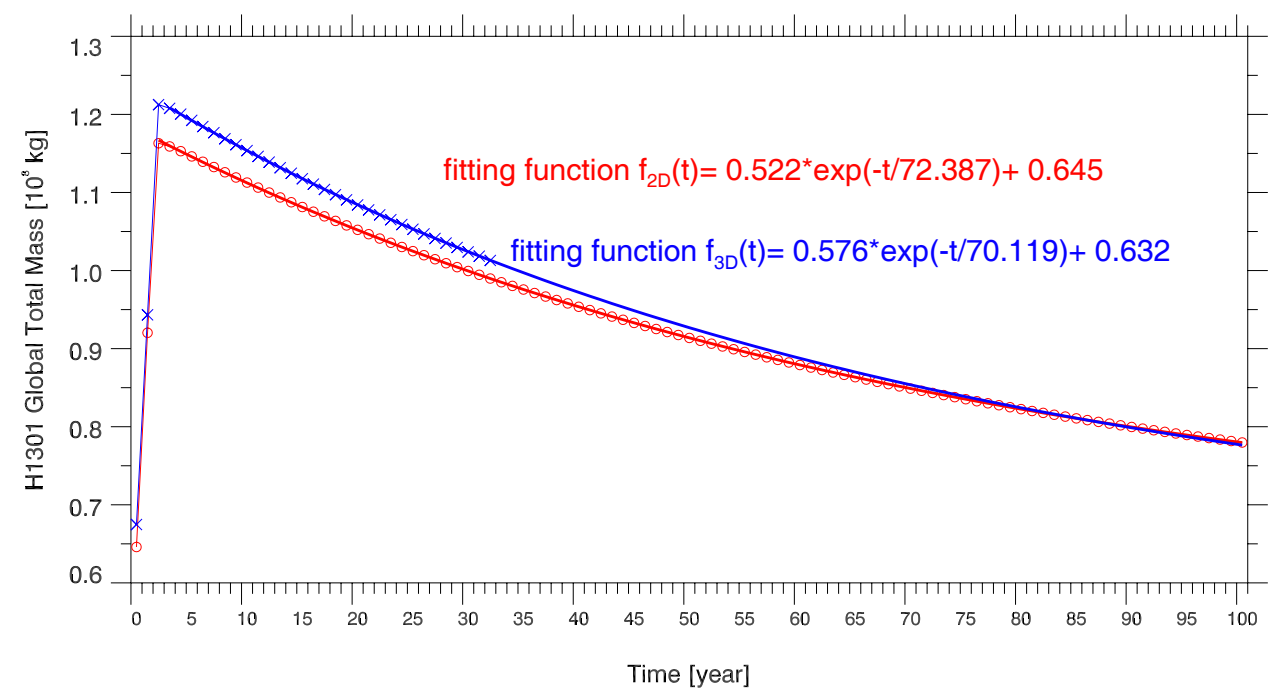

Fig. 2. Changes in global total mass of (a) Halon-1211 and (b) Halon-1301 over time after a single-year pulse injection of $10^{8} \mathrm{~kg}$. Red lines with circle marks denote outputs from the UIUC 2-D CTM and blue with cross from MOZART-3 3-D CTM. Exponential fitting functions are estimated for the decreasing mass.

14.5 years, the lifetimes are within the range of reported values 11-16 years in WMO assessments in Table 1. 2-D and 3-D model lifetimes for Halon-1301 are in reasonable agreement.

Direct GWPs for a 100-year time horizon for the simulated Halons are calculated for comparison with previous assessments. The traditional approach to estimate absolute GWPs (AGWP) for the long-lived gases uses radiative efficiency and tropospheric mixing ratios with their lifetimes (IPCC/TEAP 2005; WMO 2007). In this study, AGWPs for the Halons are evaluated using the actual time-dependent variations of 2-D and 3-D simulated mixing ratios. The tro- pospheric mixing ratios of the Halons are shown in Fig. 3. We use the $\mathrm{CO}_{2}$ AGWP value of $0.676 \mathrm{~W} \mathrm{~m}^{-2}$ ppmv $^{-1} \mathrm{yr}$ for the time horizon of 100 years in the latest ozone assessment (WMO, 2007). A radiative efficiency of 0.30 (0.32) $\mathrm{W} \mathrm{m}^{-1} \mathrm{ppbv}^{-1}$ for Halon-1211 (Halon-1301) yields 2-D model-based direct GWP of 1796 (7122) and 3-D direct GWP of 1699 (6903) (see Table 1). The direct GWP values are smaller than but compare reasonably with the reported GWP of 1890 (7140) in WMO (2007). 
Table 1. Direct and indirect Global Warming Potentials (per mass basis) of Halons relative to carbon dioxide.

\begin{tabular}{|c|c|c|c|c|c|c|c|c|}
\hline \multirow{3}{*}{$\begin{array}{l}\text { Previous and } \\
\text { present studies }\end{array}$} & \multirow{2}{*}{\multicolumn{2}{|c|}{ Lifetimes (years) }} & \multicolumn{6}{|c|}{$\begin{array}{l}\text { Global Warming Potentials } \\
\text { for } 100 \text {-years time horizon }\end{array}$} \\
\hline & & & \multicolumn{2}{|c|}{ Direct GWP } & \multicolumn{2}{|c|}{ Indirect GWP } & \multicolumn{2}{|c|}{ Net GWP } \\
\hline & $\begin{array}{l}\text { Halon- } \\
1211\end{array}$ & $\begin{array}{l}\text { Halon- } \\
1301\end{array}$ & $\begin{array}{l}\text { Halon- } \\
1211\end{array}$ & $\begin{array}{l}\text { Halon- } \\
1301\end{array}$ & $\begin{array}{l}\text { Halon- } \\
1211\end{array}$ & $\begin{array}{l}\text { Halon- } \\
1301\end{array}$ & $\begin{array}{l}\text { Halon- } \\
1211\end{array}$ & $\begin{array}{l}\text { Halon- } \\
1301\end{array}$ \\
\hline $\begin{array}{l}\text { Daniel } \\
(1995)\end{array}$ & 20 & 65 & N/A & 4460 & N/A & $\begin{array}{l}-92520 \sim \\
-15820\end{array}$ & $\begin{array}{l}-42020 \sim \\
-7100\end{array}$ & $\begin{array}{l}-88060 \sim \\
-11360\end{array}$ \\
\hline $\begin{array}{l}\text { WMO } \\
(1999)\end{array}$ & 11 & 65 & 1300 & 6900 & N/A & $\begin{array}{l}-103930 \sim \\
-16410\end{array}$ & N/A & $\begin{array}{l}-197030 \sim \\
-9510\end{array}$ \\
\hline $\begin{array}{l}\text { WMO } \\
(2003)\end{array}$ & 16 & 65 & 1860 & 7030 & $\begin{array}{l}-35220 \sim \\
-6910\end{array}$ & $\begin{array}{l}-66310 \sim \\
-13000\end{array}$ & $\begin{array}{l}-33360 \sim \\
-5050\end{array}$ & $\begin{array}{l}-59280 \sim \\
-5970\end{array}$ \\
\hline $\begin{array}{l}\text { IPCC/ } \\
\text { TEAP } \\
(2005)\end{array}$ & 16 & 65 & $\begin{array}{l}1860 \\
\pm 650\end{array}$ & $\begin{array}{l}7030 \\
\pm 2460\end{array}$ & $\begin{array}{l}-28200 \\
\pm 19600\end{array}$ & $\begin{array}{l}-32900 \\
\pm 27100\end{array}$ & $\begin{array}{l}-26340 \\
\pm 20250\end{array}$ & $\begin{array}{l}-25870 \\
\pm 29560\end{array}$ \\
\hline $\begin{array}{l}\text { WMO } \\
(2007)\end{array}$ & 16 & 65 & $\begin{array}{l}1890 \\
\pm 660\end{array}$ & $\begin{array}{l}7140 \\
\pm 2500\end{array}$ & $\begin{array}{l}-40280 \\
\pm 27120\end{array}$ & $\begin{array}{l}-49090 \\
\pm 34280\end{array}$ & $\begin{array}{l}-38390 \\
\pm 27780\end{array}$ & $\begin{array}{l}-41950 \\
\pm 36780\end{array}$ \\
\hline $\begin{array}{l}\text { 2-D } \\
\text { Model }\end{array}$ & $\begin{array}{l}14^{a} \\
(15)^{b}\end{array}$ & $\begin{array}{l}72^{a} \\
(75)^{b}\end{array}$ & 1800 & 7120 & -16290 & -36250 & -14500 & -29130 \\
\hline $\begin{array}{l}\text { 3-D } \\
\text { Model }\end{array}$ & $\begin{array}{l}11^{a} \\
(11)^{b}\end{array}$ & $\begin{array}{l}70^{a} \\
(70)^{b}\end{array}$ & 1700 & 6900 & -17050 & -37250 & -15350 & -30350 \\
\hline
\end{tabular}

a The lifetimes are e-folding times of the exponential curve fitted to the model simulated time-series of the Halons.

$\mathrm{b}$ Derived lifetimes in parenthesis are global chemical lifetimes calculated using atmospheric total burden (loading) and chemical loss-rates in the models.

\section{2 $\mathrm{O}_{3}$ response to the Halon perturbation}

The increased bromine and chlorine in the stratosphere due to the pulse perturbation injection of Halon-1211 (only bromine for Halon-1301) lead to the stratospheric ozone depletion. Temporal changes in the stratospheric ozone destruction and recovery induced by the pulse perturbation are shown in Figs. 4 and 5. The 2-D and 3-D results show similar temporal variations of global average ozone.

Ozone loss following the Halon increase accumulates at the first phase up to peak loss. Maximum ozone loss lags the peak Halon increase by 7-8 years for Halon-1211 and 1013 for Halon-1301 (Fig. 4). Ozone responses to the added Halon-1301 are much slower due to much longer lifetime of Halon-1301, 70-72 years for our model simulations which are larger than but comparable to 65 years in WMO (2003, 2007). Compared to the full 100-year 2-D simulations, the exponential curves for 3-D simulations are good fits for both Halons. The ozone, depleted due to an instantaneous Halon1211 perturbation, fully recovers and comes close to the ini- tial state within the 100 year time frame. However, this is not the case for Halon-1301, which could imply that impacts of the ozone-depleting species with longer lifetimes on the climate need to be considered over a longer time horizon.

The time-dependent impacts of the pulse injected Halon1211 on atmospheric ozone at different height levels of 2.25 (near surface), 18.75 (tropopause), 24.75 (lower stratosphere), and $45.25 \mathrm{~km}$ (upper stratosphere) indicate delayed ozone loss depending on the heights (Fig. 5). The globally averaged ozone concentrations were normalized relative to the steady-state concentration on each level. The maximum ozone depletion appears at the level near the tropopause with peak percentage depletion of about $1.2-1.4 \%$. The ozone loss near the tropopause $(18.75 \mathrm{~km})$ peaks similarly at $7-8$ years after the injected pulse emission for both 2-D and 3-D runs. Decreases in ozone losses at different levels also show exponential behaviors after the peak. Ozone changes near the surface lag changes at the other levels due to the transport time from the place of ozone depletion, the stratosphere, to the troposphere and to the surface. 
(a) Time-series of H1211 [ppt]: 2-D (red) \& 3-D (blue) H1211 perturbation runs

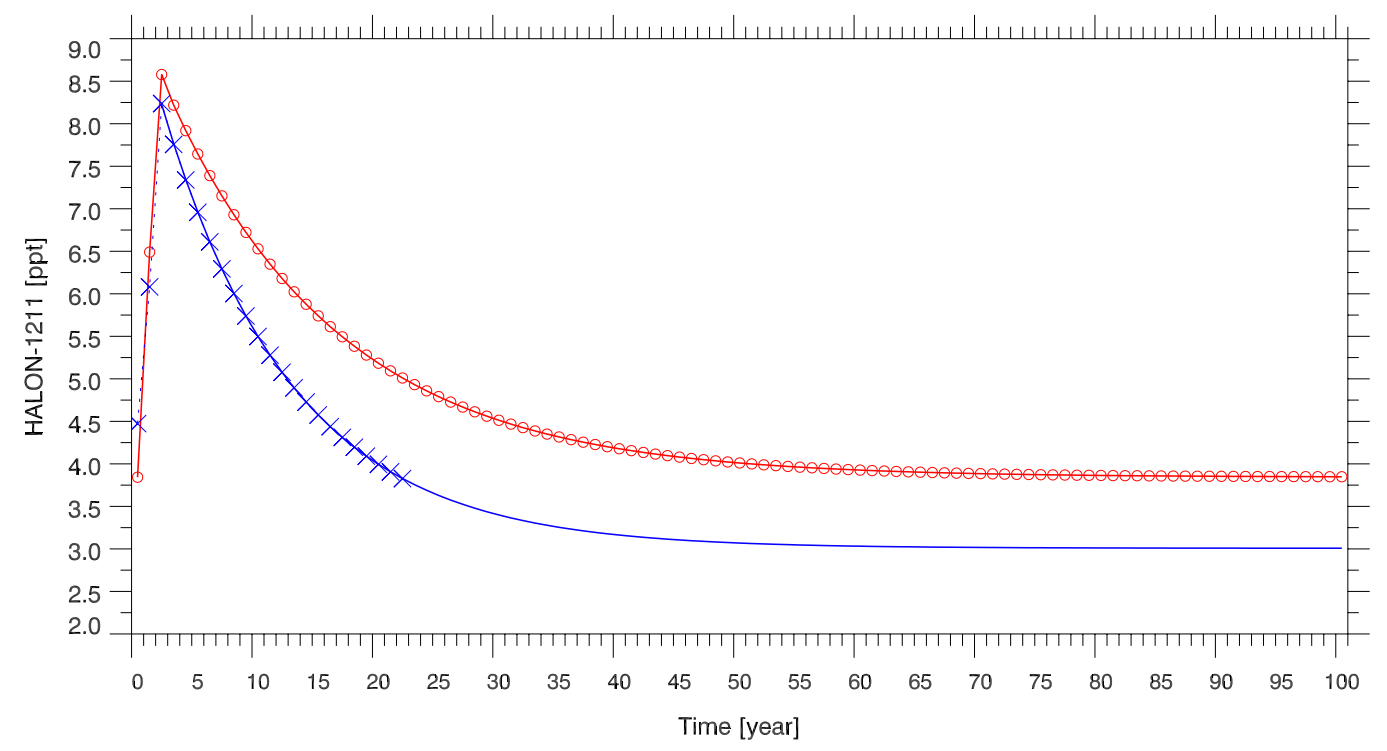

(b) Time-series of $\mathrm{H} 1301$ [ppt]: 2-D (red) \& 3-D (blue) H1301 perturbation runs

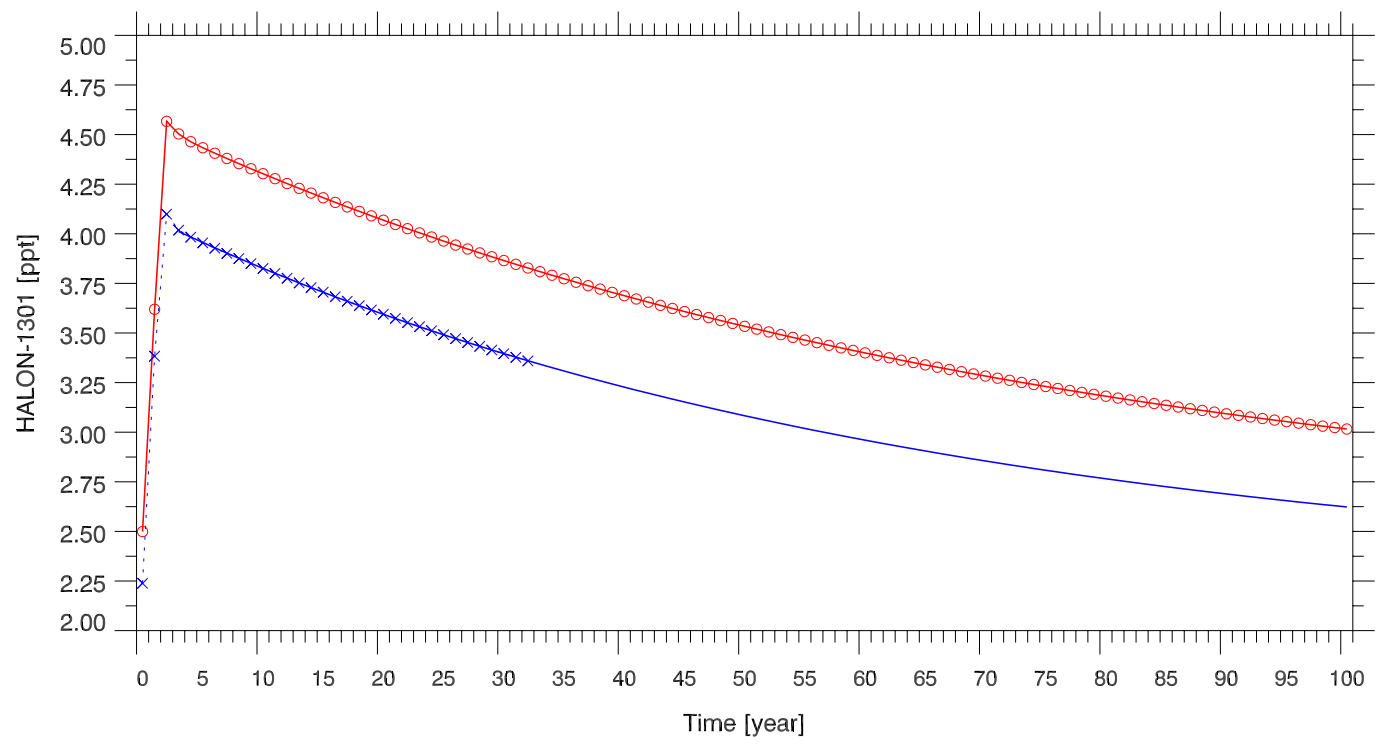

Fig. 3. Same as Fig. 2, but for tropospheric mixing ratios in ppt.

Global total ozone masses from the MOZART-3 3-D CTM are up to $0.3 \%$ smaller than those from the UIUC 2-D throughout time. Ozone recovery after peak destruction shown in time-series of simulated ozone from the 2-D model exponentially fits almost perfectly (good matches between simulated ozone and the exponential curve fits). In the 2D CTM, the global total ozone mass at the first year, when the pulse perturbation is just injected into the surface air and has little influence on ozone, matches that at the 100th year very well. The agreement between ozone masses at starting and ending years suggests the 2-D simulations really started from a steady-state atmosphere. A curve fit of exponential ozone recovery for 3-D Halon simulations represent reasonably well the temporal variation of ozone recovery after the peak loss. The difference between 2-D and 3-D ozone recovery could be attributed to differences in model characteristics such as model physics and transport time (the age of air).

Based on the simulated ozone response, temporal changes in the calculated radiative forcing resulting from the ozone destruction are expected to have an exponential variation very similar to the ozone recovery. The remaining years without 3-D simulations can thus be assumed to follow the 
(a) Time-series of global total $\mathrm{O}_{3}$ mass: 2-D (red) \& 3-D (blue) $\mathrm{H} 1211$ perturbation runs

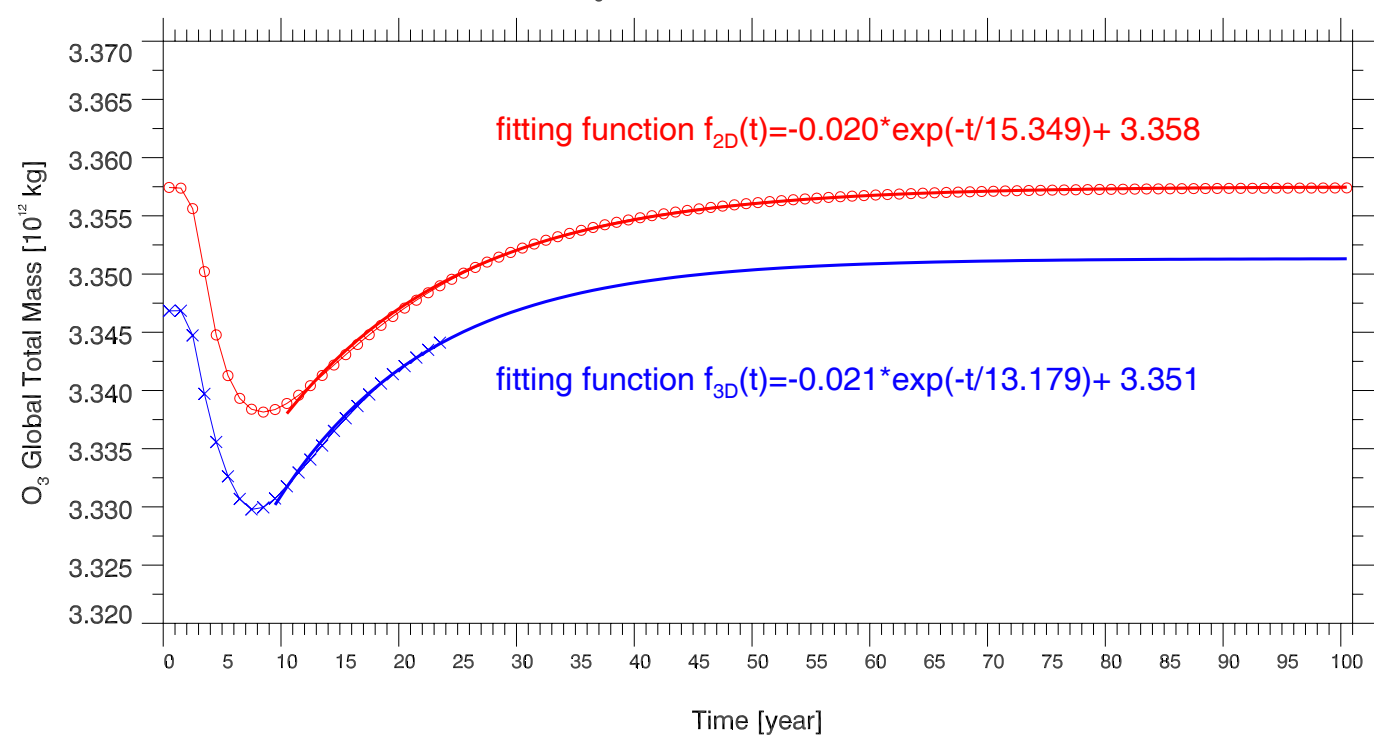

(b) Time-series of global total $\mathrm{O}_{3}$ mass: 2-D (red) \& 3-D (blue) $\mathrm{H} 1301$ perturbation run

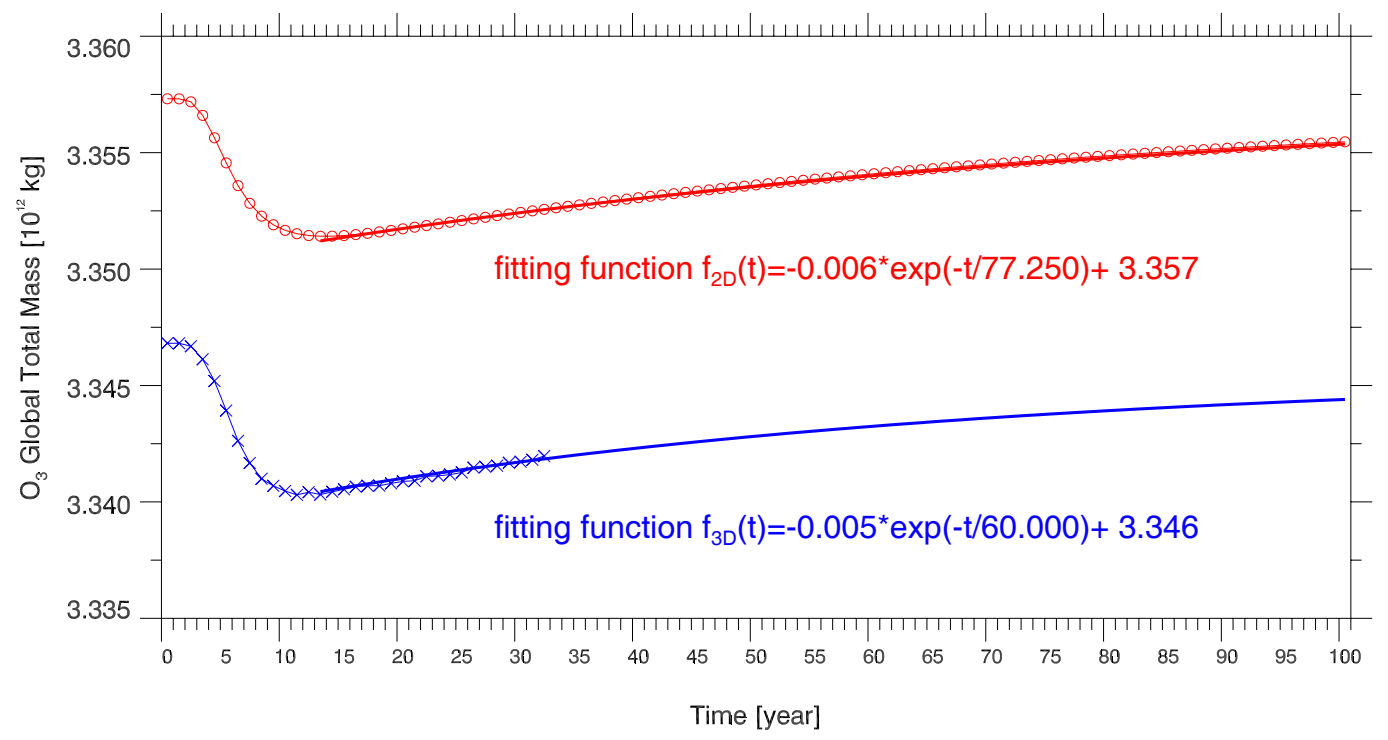

Fig. 4. Same as Fig. 2, but for ozone in $10^{12} \mathrm{~kg}$. Exponential fitting functions are estimated for the years of ozone recovery.

exponential curve and so the 100 years of cooling effects caused by ozone depletion due to the Halon perturbation can be estimated. The corresponding instantaneous radiative forcing calculations are presented in the following section.

\subsection{Radiative forcing and indirect GWPs}

We used the UIUC RTM to calculate changes in the radiative forcings (RF) due to the ozone depletion induced by the Halon perturbation. Time-series of changes in calculated RF (down radiative flux minus up flux), net radiative imbalance by ozone loss, for a 100 year time horizon are presented in Fig. 6. The change indicates the global annual mean radiative cooling at the tropopause arising from ozone depletion. Changes in the RF per added mass of each Halon at the tropopause in units of $\mathrm{W} \mathrm{m}^{-2}$ (kg Halon) $^{-1}$ show an exponential decrease of the cooling during ozone recovery. Exponential curve fits were again applied to the changes in the radiative forcing so that the cooling at longer times after the pulse could be estimated based on a curve fit.

The cooling at the 100-th year atmosphere for 2-D Halon1211 simulation is negligible (almost zero) as the atmosphere is approximately in steady-state at that time. Therefore, the fitting function for 3-D Halon-1211 simulations needs to be 
(a) Time-series of percentage change in $\mathrm{O}_{3}$ [\%]: 2-D $\mathrm{H} 1211$ perturbation run

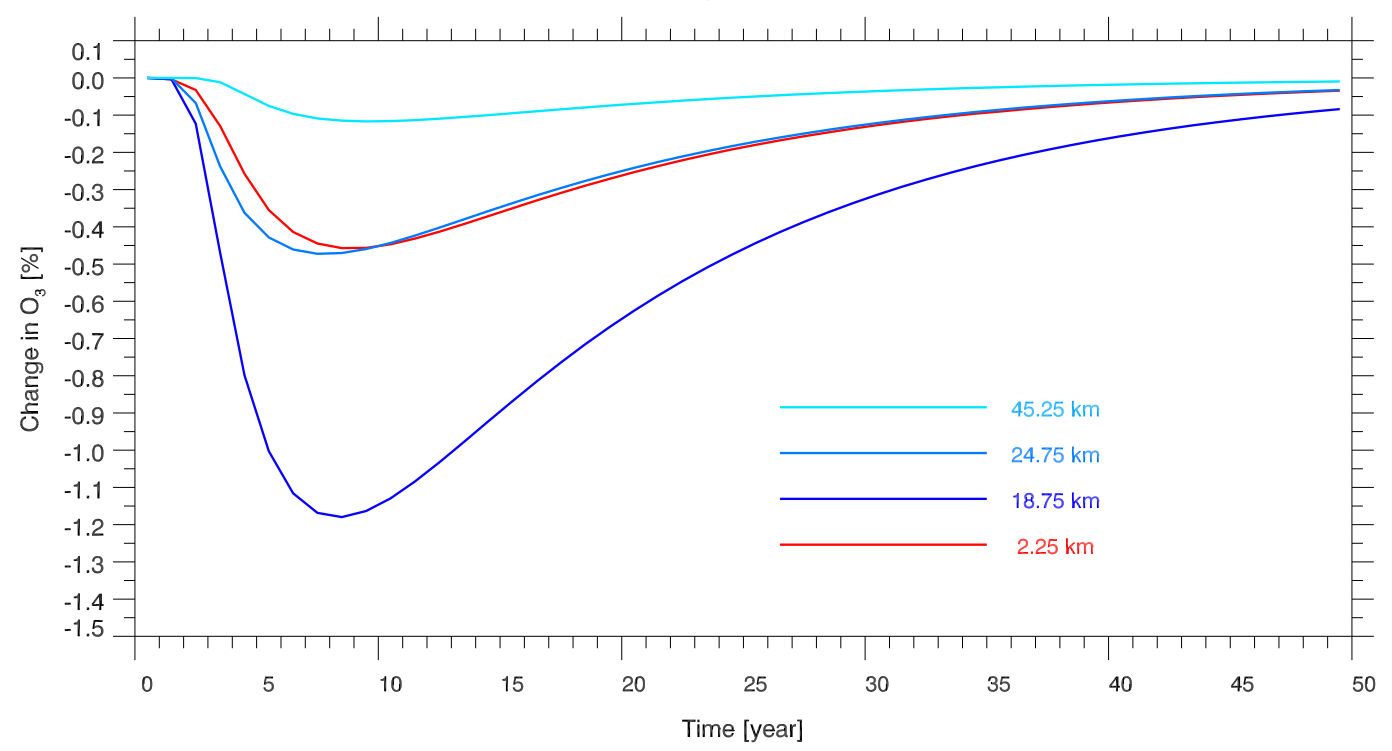

(b) Time-series of percentage change in $\mathrm{O}_{3}$ [\%]: 3-D $\mathrm{H} 1211$ perturbation run

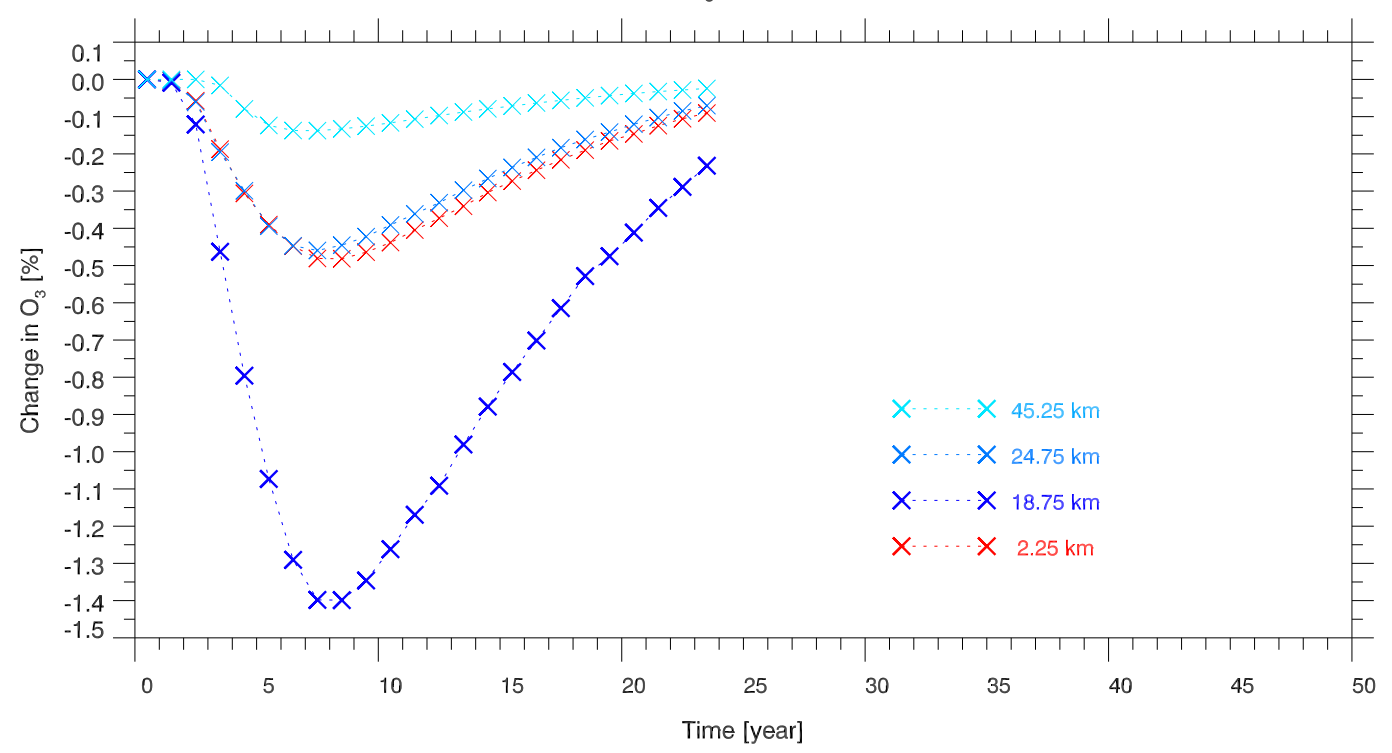

Fig. 5. Percentage change of globally averaged ozone depletion over time on selected height levels for (a) 2-D and (b) 3-D perturbation runs.

tuned to approach zero at the infinite time, which yields the best curve fit. The magnitudes of all the 3 -D radiative coolings after the peak cooling were adjusted so that the value of applied curve fit at the infinite time is zero. However, the radiative cooling variations before the peak cooling were obtained just by subtracting the two RFs from the perturbation and standard runs without the adjustment. After this subtraction, the first year cooling gets to be very close to zero as shown in Fig. 6, which means the validity of two parallel simulations used to overcome the issue that the initial 3-D model atmosphere is not at the steady-state. This builds ro- bustness of our approach doing two parallel simulations with and without the first year perturbation.

For Halon-1211 (Halon-1301), the largest 2-D and 3-D radiative cooling effects appear at the 8th (14th) year, similar to the time of the peak ozone depletion. The 3-D peak values are larger than the $2-\mathrm{D}$ value. Radiative forcing changes caused by the instantaneous releases of Halons were time-integrated on a per mass basis over the 100-year time horizon. As described in the previous section, the ratio of the 100-year cumulative radiative forcing to the 100year $\mathrm{CO}_{2}$ forcing is the indirect GWP. The indirect GWPs 
(a) Change in RF (downwelling-upwelling) at the tropopause by $\mathrm{H} 1211$ perturbation

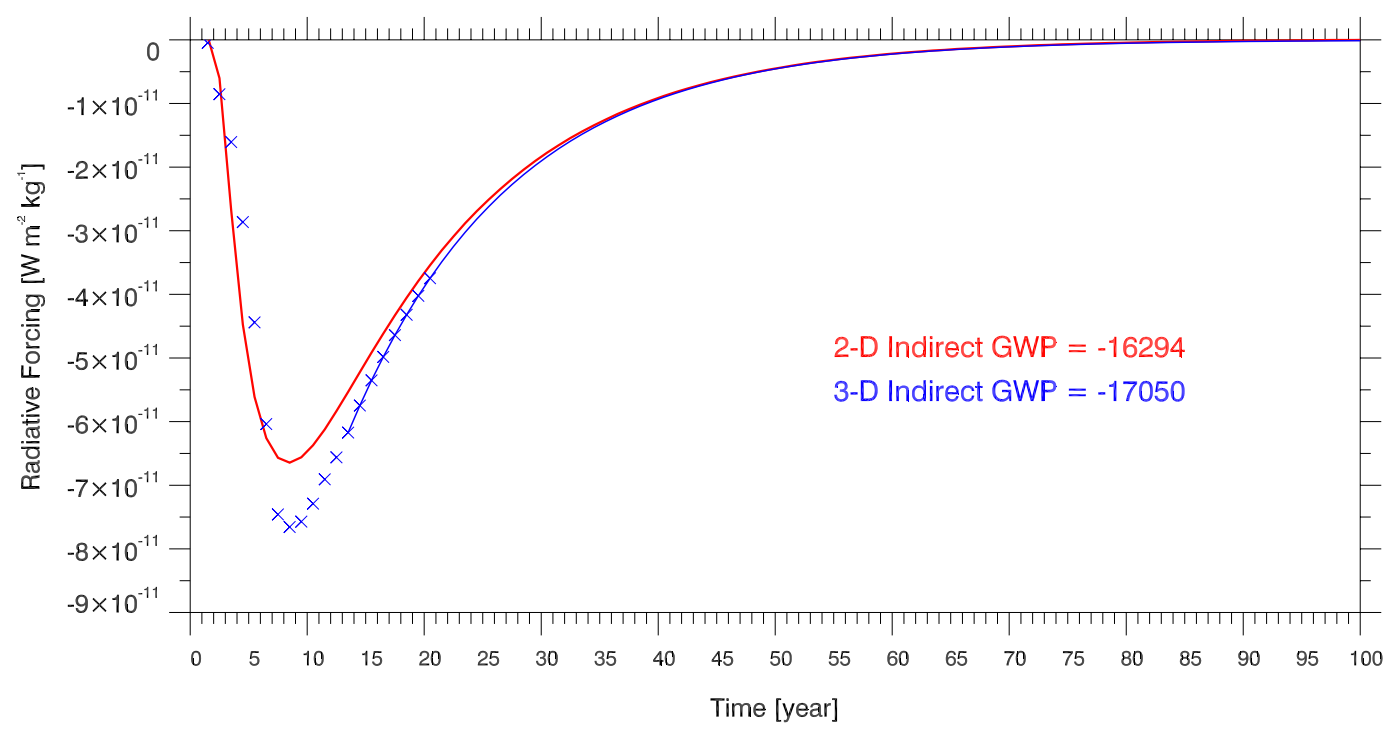

(b) Change in RF (downwelling-upwelling) at the tropopause by $\mathrm{H} 1301$ perturbation

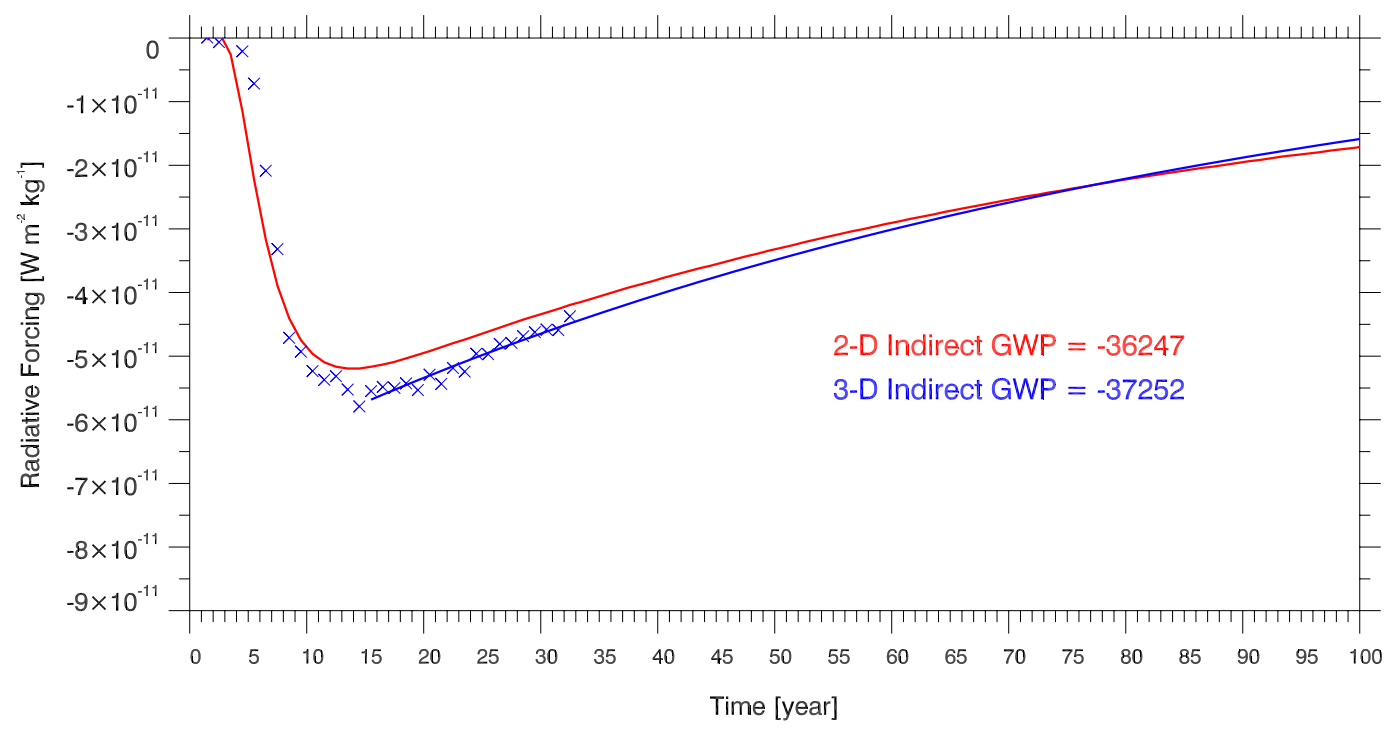

Fig. 6. Time-series of RF changes due to (a) Halon-1211 and (b) Halon-1301 perturbations. The best fits are estimated for the years of ozone recovery.

for Halon-1211 (Halon-1301) are calculated to be -16294 $(-36247)$ for 2-D model outputs and $-17050(-37252)$ for 3-D model, using the same reported $\mathrm{CO}_{2}$ AGWP (WMO, 2007). Compared to the previously published indirect GWPs in Table 1, our calculated values are smaller but those for Halon-1301 are close to those in IPCC/TEAP (2005) and WMO (2007).

A shorter lifetime should somewhat reduce the derived indirect GWPs but the differences between the Halon-1211 lifetime from WMO (2007) and from the model is within the uncertainty of the WMO value. As indicated by the longer lifetime we derive for Halon-1301, the large decrease in the indirect GWPs would still be derived. Both the 2-D and 3$\mathrm{D}$ models produce alpha values that are close to 60 (WMO, 2007). The ozone RF depends on the change in ozone distribution and we have calculated the ozone RF due to changes in chlorine and bromine from 1979 and 1997 using our 2-D CTM and RTM which is $-0.11 \mathrm{~W} \mathrm{~m}^{-2}$ smaller than the value of $-0.15 \pm 0.10 \mathrm{~W} \mathrm{~m}^{-2}$ used in the previous analyses (WMO, 2007). The ozone RF could possibly explain the smaller Indirect GWP derived here since alpha values are similar. 


\section{Discussion and conclusions}

The 2-D CTM simulations and accompanying radiative forcing calculations are conducted for a complete 100 year time horizon to derive indirect GWPs of two major Halons. The 3-D CTM is computationally too expensive to be run for enough years to reach a (near) steady-state atmosphere especially when modeled atmospheric variations of Halons are driven by surface emissions instead of the specified concentrations at the lowest level of the model. The two parallel 3-D CTM simulations of standard versus perturbation cases for each Halon are shown to reasonably account for this difficulty. The huge computational demand to complete a 100year 3-D simulation for each of Halons has been overcome by applying an exponential curve fit to 23 years of simulation for Halon-1211 and 32 years for Halon-1301. More years of simulations are needed for Halon-1301 with longer lifetime, about 70 to 72 years estimated in this study. The direct GWPs and lifetimes are estimated with simulated temporal variations of the Halons. The resulting direct and indirect GWPs as well as lifetimes are summarized in Table 1. Published values in major assessments are also included for comparison.

The 2-D and 3-D CTM simulations show reasonable temporal variations of the Halons and resulting ozone changes in the atmosphere, yielding consistent e-folding lifetimes and direct GWPs. The validity of the 2-D and 3-D indirect GWPs is partially guaranteed by the agreement between the e-folding lifetimes estimated from a curve fit for modeled exponential decrease of global total mass and model chemical lifetimes derived from atmospheric total burden (loading) and chemical loss. Moreover, the credibility of our current simulations seems to be achieved because direct GWP values as well as lifetimes are generally consistent relative to the previous assessments.

Our approach of explicitly calculating the indirect GWPs using atmospheric models is an improvement beyond previous evaluations in that our indirect GWP calculations are not based on a parameterization approach using the EESC index. The new assessments of indirect GWPs for Halons do not assume the relationship among stratospheric ozone depletion, inorganic chlorine and bromine loading (no need to use fractional release factors, alpha values, assumed transport time, etc.), and radiative forcing. It thus does not depend on the uncertainties unavoidable in the previous traditional approach and more closely matches the desired concept of the (indirect) GWP. It is mainly because of the explicit calculation using atmospheric models. Our model-based explicit calculation can thus be used as a more robust advancement for obtaining indirect GWPs of Halons, relative to the approach by Daniel et al. (1995). However, it is worth noting that this study is affected by uncertainties in the reported $\mathrm{CO}_{2}$ AGWP and by uncertainties associated with the models adopted for this study, for example in the use of fixed surface boundary conditions for long-lived gases and in the use of climatolog- ical meteorological fields. Also, temperature feedback between ozone and climate is not fully considered. As noted in previous studies (e.g., Hansen et al., 1997), the effect of radiative forcing on climate is dependent on the distribution of the perturbation of ozone both vertically and horizontally.

Recent development of coupled chemistry climate models such as the Whole Atmosphere Community Climate Model (WACCM) from the National Center for Atmospheric Research (NCAR) enable the study of interactions between ozone and climate in the stratosphere. However, huge computational demands by WACCM kept us from using it for this study. Another aspect involves uncertainties in understanding the changes in meteorological fields related to the effects of the Halons on ozone. Further study using a model like WACCM is therefore needed. The other difficulty with using a GCM in such a study is that natural climatic variability will further complicate interpretation of the results.

The indirect GWPs for Halon-1211 derived here are much smaller than recently published results (IPCC/TEAP, 2005; WMO, 2007). However, it is still much larger by about a factor of ten compared to its direct effect. The indirect effect of Halon-1301 is more than double that of the Halon-1211 and much larger than its own direct warming effect. These analyses suggest that the traditional approach for deriving indirect GWPs is not sufficiently accurate and that global CTMs can be effective tools for these derivations.

Acknowledgements. This research was supported in part by the U.S. Environmental Protection Agency using computer resources at the University of Illinois' National Center for Supercomputing Applications (NCSA). This research also used computer resources of the Department of Energy's National Energy Research Supercomputing Center (NERSC). Daeok Youn was supported in part by the Korea Meteorological Administration Research and Development Program under grant CATER 2007-3205 and Jintai Lin by U.S. National Science Foundation under ATM-0635548.

Edited by: J. B. Burkholder

\section{References}

Briegleb, B. P.: Delta-Eddington Approximation for Solar Radiation in the NCAR Community Climate Model, J. Geophys. Res., 97, 7603-7612, 1992a.

Briegleb, B. P.: Longwave Band Model for Thermal Radiation in Climate Studies, J. Geophys. Res., 97, 11 475-11 485, 1992 b.

Considine, D. B., Douglass, A. R., Connell, P. S., Kinnison, D. E., and Rotman, D. A.: A polar stratospheric cloud parameterization for the global modeling initiative three-dimensional model and its response to stratospheric aircraft, J. Geophys. Res., 105, 3955-3973, 10.1029/1999JD900932, 2000.

Coy, L. and Swinbank, R.: Characteristics of stratospheric winds and temperatures produced by data assimilation, J. Geophys. Res, 102, 25763-25781, 1997.

Daniel, J. S., Solomon, S., and Albritton, D. L.: On the Evaluation of Halocarbon Radiative Forcing and Global Warming Potentials, J. Geophys. Res., 100, 1271-1285, 1995. 
Daniel, J. S, Velders, G. J. M., Douglass, A. R., Forster, P. M. D., Hauglustaine, D. A., Isaksen, I. S. A., Kuijpers, L. J. M., McCulloch, A., and Wallington, T. J.: Halocarbon Scenarios, Ozone Depletion Potentials, and Global Warming Potentials, Chapter 8 in Scientific Assessment of Ozone Depletion: 2006, Global Ozone Research and Monitoring Project - Report No. 50, World Meteorological Organization, Geneva, Switzerland, 572 pp., 2007.

DeMore, W. B., Sander, S. P., Golden, D. M., Hampson, R. F., Kurylo, M. J., Howard, C. J., Ravishankara, A. R., Kolb, C. E., and Molina, M. J.: Chemical Kinetics and Photochemical Data for Use in Stratospheric Modeling, Evaluation Number 12, Jet Propulsion Laboratory (JPL) Publication 97-4, Pasadena, California, 1997.

Forster, P., Ramaswamy, V., Artaxo, P., Berntsen, T., Betts, R., Fahey, D. W., Haywood, J., Lean, J., Lowe, D. C., Myhre, G., Nganga, J., Prinn, R., Raga, G., Schulz, M., and Van Dorland, R.: Changes in Atmospheric Constituents and in Radiative Forcing, in: Climate Change 2007: The Physical Science Basis. Contribution of Working Group I to the Fourth Assessment Report of the Intergovernmental Panel on Climate Change, edited by: Solomon, S., Qin, D., Manning, M., Chen, Z., Marquis, M., Averyt, K. B., Tignor M., and Miller H. L., Cambridge University Press, Cambridge, United Kingdom and New York, NY, USA, 2007.

Garcia, R. R., Marsh, D. R., Kinnison, D. E., Boville, B. A., and Sassi, F.: Simulation of secular trends in the middle atmosphere, 1950-2003, J. Geophys. Res., 112, D09301, doi:10.1029/2006JD007485, 2007.

Guillas, S., Stein M. L., Wuebbles, D. J., and Xia, J.: Using chemistry-transport modeling in statistical analysis of stratospheric ozone trends from observations, J. Geophys. Res., 109, D22303, 10.1029/2004JD005049, 2004.

Hansen, J., Sato, M., and Ruedy, R.: Radiative forcing and climate response, J. Geophys. Res., 102, 6831-6864, 1997.

Horowitz, L., Walters, S., Mauzerall, D., Emmons, L., Rasch, P., Granier, C., Tie, X., Lamarque, J.-F., Schultz, M., Tyndall, G., Orlando, J., and Brasseur, G.: A global simulation of tropospheric ozone and related tracers: Description and evaluation of MOZART, version 2. J. Geophys. Res., 108, 4784, doi:10.1029/2002JD002853, 2003.

Intergovernmental Panel on Climate Change (IPCC): Climate Change, The IPCC Scientific Assessment, edited by: Houghton, J. T., Jenkins, G. J., Ephraums, J. J., (Chapter 2, Radiative Forcing on Climate, Shine, K. P., Derwent, R. G., Wuebbles, D. J., and Morcrette, J.-J.), Cambridge University Press, New York, 1990.

Intergovernmental Panel on Climate Change (IPCC): Climate Change 2001: The Scientific Basis. Contribution of Working Group I to the Third Assessment Report of the Intergovernmental Panel on Climate Change, edited by: Houghton, J. T., Ding, Y., Griggs, D. J., Noguer, M., van der Linden, P. J., and Xiaosu, D., Cambridge University Press, Cambridge, UK and New York, 881 pp., 2001.

Intergovernmental Panel on Climate Change and Technology and Economic Assessment Panel (IPCC/TEAP): IPCC/TEAP Special Report on Safeguarding the Ozone Layer and the Global Climate System: Issues Related to Hydrofluorocarbons and Perfluorocarbons, edited by: Metz, B., Kuijpers, L., Solomon, S.,
Andersen, S. O., Davidson, O., Pons, J., de Jager, D., Kestin, T., Manning, M., and Meyer, L. A., Cambridge University Press, New York, 478 pp., 2005.

Intergovernmental Panel on Climate Change (IPCC): Climate Change 2007: The Physical Science Basis. Contribution of Working Group I to the Fourth Assessment Report of the Intergovernmental Panel on Climate Change, edited by: Solomon, S., Qin, D., Manning, M., Chen, Z., Marquis, M., Averyt, K.B., Tignor, M., and Miller, H.L., Cambridge University Press, New York, 996 pp., 2007.

Jain, A. K., Briegleb, B. P., Minschwaner, K., and Wuebbles, D. J.: Radiative forcings and global warming potentials of 39 greenhouse gases, J. Geophys. Res., 105, 20 773-20 790, 2000.

Joshi, M., Shine, K., Ponater, M., Stuber, N., Sausen, R., and Li, L.: A comparison of climate response to different radiative forcings in three general circulation models: towards an improved metric of climate change, Clim. Dynam., 20, 843-854, 2003.

Kinnison, D. E., Brasseur, G. P., Walters, S., Garcia, R. R., Marsh, D. R., Sassi, F., Harvey, V. L., Randall, C. E., Emmons, L., Lamarque, J. F., Hess, P., Orlando, J. J., Tie, X. X., Randel, W., Pan, L. L., Gettelman, A., Granier, C., Diehl, T., Niemeier, U., and Simmons, A. J.: Sensitivity of chemical tracers to meteorological parameters in the MOZART-3 Chemical Transport Model, J. Geophys. Res., 112, D20302, doi:10.1029/2006JD007879, 2007.

Kotamarthi, V. R., Wuebbles, D. J., and Reck, R. A.: Effects of nonmethane hydrocarbons on lower stratospheric and upper tropospheric 2-D zonal average model chemical climatology, J. Geophys, Res., 104, 21 537-21 547, 1999.

Lacis, A. A., Wuebbles, D. J., and Logan, J. A.: Radiative Forcing of Climate by Changes in the Vertical Distribution of Ozone, J. Geophys. Res., 95, 9971-9981, 1990.

Li, Y., Patten, K. O., Youn, D., and Wuebbles, D. J.: Potential impacts of $\mathrm{CF}_{3} \mathrm{I}$ on ozone as a replacement for $\mathrm{CF}_{3} \mathrm{Br}$ in aircraft applications, Atmos. Chem. Phys., 6, 4559-4568, 2006, http://www.atmos-chem-phys.net/6/4559/2006/.

Miller, A. J., Nagatani, R. M., Flynn, L. E., Kondragunta, S., Beach, E., Stolarski, R., McPeters, R. D., Bhartia, P. K., De-Land, M. T., Jackman, C. H., Wuebbles, D. J., Patten, K. O., and Cebula, R. P.: A cohesive total ozone data set from the SBUV(/2) satellite system, J. Geophys. Res., 107, 4701, doi:10.1029/2001JD000853, 2002.

Naik, V., Jain, A. K., Patten, K. O., and Wuebbles, D. J.: Consistent sets of atmospheric lifetimes and radiative forcings on climate for CFC replacements: HCFCs and HFCs, J. Geophys. Res., 105, 6903-6914, 2000.

Newman, P. A., Daniel, J. S., Waugh, D. W., and Nash, E. R.: A new formulation of equivalent effective stratospheric chlorine (EESC), Atmos. Chem. Phys., 7, 4537-4552, 2007, http://www.atmos-chem-phys.net/7/4537/2007/.

Newman, P. A., Nash, E. R., Kawa, S. R., Montzka, S. A., and Schauffler, S. M.; When will the Antarctic ozone hole recover?, Geophys. Res. Lett., 33, L12814, doi:10.1029/2005GL025232, 2006.

Pan, L. L., Wei, J. C., Kinnison, D. E., Garcia, R.R., Wuebbles, D. J., and Brasseur, G. P.: A set of diagnostics for evaluating chemistry-climate models in the extratropical tropopause region, J. Geophys. Res., 112, D09316, doi:10.1029/2006JD007792, 2007. 
Pfister, G. G., Emmons, L. K., Hess, P. G., Lamarque, J.-F., Orlando, J. J., Walters, S., Guenther, A., Palmer, P. I., and Lawrence, P. J.: Contribution of isoprene to chemical budgets: A model tracer study with the NCAR CTM MOZART-4, J. Geophys. Res., 113, D05308, doi:10.1029/2007JD008948, 2008.

Ramaswamy, V., Schwarzkopf, M. D., and Shine, K. P.: Radiative forcing of climate from halocarbon induced global stratospheric ozone loss, Nature, 355, 810-812, 1992.

Rothman, L. S., Jacquemart, D., Barbe, A., Chris Benner, D., Birk, M., Brown, L. R., Carleer, M. R., Chackerian Jr., C., Chance, K., Coudert, L. H., Dana, V., Devi, V. M., Flaud, J.-M., Gamache, R. R., Goldman, A., Hartmann, J.-M., Jucks, K. W., Maki, A. G., Mandin, J.-Y., Massie, S. T., Orphal, J., Perrin, A., Rinsland, C. P., Smith, M. A. H., Tennyson, J., Tolchenov, R. N., Toth, R. A., Vander Auwera, J., Varanasi, P., and Wagner, G.: The HITRAN 2004 molecular spectroscopic database, J. Quant. Spectrosc. Ra., 96, 139-204, ISSN 0022-4073, doi:10.1016/j.jqsrt.2004.10.008, 2005.

Sander, S. P., Friedl, R. R., Golden, D. M., Kurylo, M. J., Huie, R. E., Orkin, V. L., Moortgat, G. K., Ravishankara, A. R., Kolb, C. E., Molina, M. J., and Finlayson-Pitts, B. J.: Chemical kinetics and photochemical data for use in atmospheric studies, NASA/JPL Publication 02-25. Pasadena, California, 334 pp., 2003.

Sassi, F., Garcia, R. R., Boville, B. A., and Liu, H.: On temperature inversions and the mesospheric surf zone, J. Geophys. Res., 107, 4380, doi:10.1029/2001JD001525, 2002.

Stamnes, K., Tsay, S.-C., Wiscombe, W., and Jayaweera, K.: Numerically stable algorithm for discrete-ordinate-method radiative transfer in multiple scattering and emitting layered media, Appl. Optimizat., 27, 2502-2509, 1988.
Velders, G. J. M., Anderson S. O., Daniel J. S., Fahey D. W., and McFarland, M.: The importance of the Montreal Protocol in protecting climate, P. Natl. Acad. Sci. USA, 104, 4814-4819, 2007.

World Meteorological Organization (WMO): Scientific Assessment of Ozone Depletion: 1994, Global Ozone, Research and Monitoring Project - Report 37, Geneva, Switzerland, 1995.

World Meteorological Organization (WMO): Scientific Assessment of Ozone Depletion: 1998, Global Ozone, Research and Monitoring Project - Report 44, Geneva, Switzerland, 1999.

World Meteorological Organization (WMO): Scientific Assessment of Ozone Depletion: 2002, Global Ozone, Research and Monitoring Project - Report 47, Geneva, Switzerland, 2003.

World Meteorological Organization (WMO): Scientific Assessment of Ozone Depletion: 2006, Global Ozone, Research and Monitoring Project - Report 50, Geneva, Switzerland, 2007.

Wuebbles, D. J.: Weighing functions for ozone depletion and greenhouse gas effects on climate, Annu. Rev. Energ. Env., 20, 45-70, 1995.

Wuebbles, D. J., Patten, K. O., Johnson, M. T., and Kotamarthi, R.: The new methodology for Ozone Depletion Potentials of shortlived compounds: n-propyl bromide as an example, J. Geophys. Res., 106, 14 551-14 571, 2001.

Wuebbles, D. J. and Patten, K. O.: Three-Dimensional Modeling of HCFC-123 in the Atmosphere: Assessing Its Potential Environmental Impacts and Rationale for Continued Use, Environ. Sci. Technol., 43, 3208-3213, 2009.

Youn, D., Choi, W., Lee, H., and Wuebbles, D. J.: Interhemispheric differences in changes of long-lived tracers in the middle stratosphere over the last decade, Geophys. Res. Lett., 33, L03807, doi:10.1029/2005GL024274, 2006. 